\title{
The Role of Fatalism in Resilience to Food Price Volatility in Bangladesh
}

\author{
Ferdous Jahan, Mamun-ur-Rashid and Sharif A. Wahab
}

\begin{abstract}
Millions of people in Bangladesh suffer from hunger, unpredictable and unstable livelihoods, precarious living conditions and social injustice. Yet they survive and become resilient. However, the resilience achieved by the poor is minimal and incremental in nature and does not result in their wellbeing. Based on three years of qualitative research, this article attempts to understand the nature of and pathways to 'resilience of the poor people'. The article argues that poor people's approach to 'resilience' is twofold. First, they perceive their poverty and associated problems as 'Allah's will', with not much to be done about it. At the same time, they engage in continuous innovative practices to survive. These two worldviews together ('fatalism' and 'self-help') make the poor 'resilient'. This also 'partially' explains the absence of strong activism, collective action and protests within a context of state failure (in terms of ensuring rights and entitlements to its citizens).
\end{abstract}

\section{Introduction}

Bangladesh features poor and unaccountable governance and political unrest in response to widespread corruption, rights violation and powerholder impunity. Despite this, performance on the Human Development Index (HDI) has been improving over the years and economic and social development trends have been impressive. ${ }^{1}$ While political actors, bureaucrats, the private sector and international development partners claim their share of contribution towards the country's development, the narratives of struggle of the ordinary people behind these achievements often remain unnoticed, suggesting that we may be missing part of the solution to persistent poverty in an economy increasingly affected by global forces. Development efforts notwithstanding, millions of people in Bangladesh continue to suffer from hunger, unpredictable and unstable livelihoods, precarious living conditions and social injustice.

They survive and adapt, but cannot transform their lives because of the lack of an enabling governance environment. ${ }^{2}$ It could be argued that their resilience starts with coping and stops at adaptation, and does not entail the third vital element of resilience, that of transforming their ways of life so that their wellbeing is protected or advanced (Béné et al. 2012).

Instead of asserting and demanding their rights from the state to live well, people struggle on their own meagre resources, informed by a worldview shaped by a mix of self-help, faith and fatalism. Many people perceive their poverty and its associated problems and their unaccountable government as 'God's will' and think that there is not much to be done about them. At the same time, they engage in continuous innovative practices to survive. These worldviews of faith, fatalism and self-help make them appear resilient within a context of deprivation, enabling them to cope and adapt to a certain degree to the changing conditions of life. The combination also partially explains the absence of strong activism, collective action or protests within a context of failure by a democratically-elected state to ensure the rights and entitlements of its citizens.

This article attempts to understand the nature of and pathways to resilience of people living precariously and in poverty in Bangladesh, and the role of self-help and religious faith in their wellbeing. It aims to highlight that the muchdiscussed resilience of the Bangladeshi people can be overstated, and excludes consideration of the personal costs and ill-being generated by crisiscoping. It also aims to draw attention to the safety net roles played by self-reliance and religious faith as psychological and social protection.

This article is based on evidence gathered over three years of qualitative research, which studied the wellbeing of people living on low and precarious 


$\begin{array}{ccc}\text { stability } & \text { flexibility } & \text { change } \\ \begin{array}{c}\text { Absorptive coping } \\ \text { capacity } \\ \text { (persistence) }\end{array} & \text { Adaptive capacity } & \begin{array}{c}\text { Transformative } \\ \text { capacity }\end{array} \\ \text { (incremental adjustment) } & \text { (transformational responses) }\end{array}$

Source Béné et al. (2012).

incomes in the aftermath of the food price shocks of 2007-08 and 2011-12, building on earlier research into the social impacts of economic crisis (Heltberg et al. 2012; Rashid, Hasan and Hossain 2012). The research provides in-depth understanding of the ways in which food price volatility affects poor people's lives and how they cope with its effects (Jahan et al. 2013). It has contributed to the now significant body of evidence showing that recent food price volatility in Bangladesh (2007-12) caused cuts in consumption, substitution for lower value and less diverse diets and cuts in meal size and frequency (Matin 2009; World Bank 2012; Rashid et al. 2012), with particularly serious implications for women (Levay et al. 2013; Hossain and Jahan 2014).

In Bangladesh, three sites were selected for the study: an agro-based rural area with a high proportion of people living with extreme poverty (Naogaon District of north-western Bangladesh), an urban slum with a mixed economy including a large number of readymade garments industry workers (Dhaka), and a former rice-producing community affected by the 2009 cyclone Aila (Khulna District in southern Bangladesh). People have been migrating from rural to urban areas in recent times to access better livelihood opportunities, so that although the urban and rural communities live in separate physical spaces, they share broadly similar beliefs and worldviews. A key issue for urban migrants is how to adjust to a new socioeconomic structure within their traditional belief system.

\section{Wellbeing and resilience}

The concept of wellbeing used in this article is based upon the capability approach formulated by Sen: 'People have the freedoms (capabilities) to lead the kind of lives they want to lead, to do what they want to do and be the person they want to be' (Sen 2000: 9). A key strength of a wellbeing approach is its ability to combine objective with subjective measures of poverty. This approach uses a bottom-up perspective, and considers community preferences and priorities more important than that of the universal indicators (Gupte and te Lintelo 2015: 14). In the present research, two key factors of wellbeing are in focus - current needs and economic status (Jahan et al. 2013).

A useful way to conceptualise resilience in relation to people's wellbeing is to understand it as the 'ability to resist, recover from, or adapt to the effects of a shock or a change' (Mitchell and Harris 2012: 2, cited in Béné et al. 2012). We use the 3D resilience framework developed by Béné et al. (2012) to explore the ways in which people in the three study locations have been responding to sudden and sustained food price rises over the past few years.

Resilience emerges as the result of absorptive, adaptive and transformative capacities, each leading to different outcomes: persistence, incremental adjustment, or transformational responses. When the absorptive capacity exhausts, people will adapt and make adjustments or incremental changes to continue functioning without major qualitative changes (Cutter et al. 2008). If the change required is so large that it surpasses the adaptive capacity of the household or individual, community or system, a process of transformation will take place, resulting in alterations in the individual or community's primary structure and function. This can be a deliberate process, initiated by the people involved, or it can be forced on them by changing environmental or socioeconomic conditions (Béné et al. 2012).

\section{Coping and adapting to food price volatility} 3.1 Coping with sudden food price rises

To deal with rising food prices, participants in the research adopted different strategies. 
Cutting spending on food and non-food items to cope with food price volatility is common. One respondent household spent the equivalent of US\$4.36 in 2011 for one day's groceries, but the costs for the same food items in the same quantities went up to US $\$ 5.27$ in 2012 - a rise of 21 per cent - without major changes in that household's income. Consequently, the household bought fewer food items and stopped buying non-essential items (both food and non-food).

For people whose primary spending was already on food, cutting costs meant eating less. A male agricultural day labourer ${ }^{3}$ from Naogaon commented, 'We live by physical work. Our children are growing up. We both need sufficient amounts of different food items to be active. Currently, we are just surviving by consuming the minimum we can afford.' A female garment worker ${ }^{4}$ from Dhaka slum explained, 'When the price of rice was affordable, I used to cook $1.5 \mathrm{~kg}$ of rice for my household members. Now I end up cooking 1 kg.' Others avoid using costly spices in curry; for instance, a housemaid ${ }^{5}$ from the same slum said, 'Since [the] last few weeks, I do not use onions in cooking as the cost has grown higher'. Respondents add water to increase the volume of the gravy of the curry.

In rural markets, customers have limited food options, so when prices rise they stop eating those items. Most rural respondents could not afford meat, eggs or fish. According to one fisherman ${ }^{6}$ from Naogaon, 'Almost 90 per cent of the people living in this area are poor. The income of the poor people has not increased at all or the rise in income is insignificant. As a result, we normally avoid buying meat. A few of us try to eat it once a month.' Urban markets offer multiple options. A woman shopper ${ }^{7}$ in Dhaka commented, 'I first look for the items that are almost rotten. These cost less than the fresh items.' A rickshaw puller ${ }^{8}$ living in Dhaka explained, 'This year [2013] we are consuming carp fish more. Although my son likes Hilsha fish, it costs too much.' A similar strategy is followed for rice. Coarse rice bulked out with crushed stones tends to be cheaper than good quality fine rice, so people switch to cheaper (poorer quality) varieties. To reduce the use of increasingly costly fuel, poor people cook once a day; this practice works during winter months, but in the warmer seasons food often gets stale and people frequently suffer from diarrhoeal diseases.

People eat food they preferred to avoid previously. In Dhaka, certain types of low-quality (and banned) piranha fish are available in local markets. People eat chaat (thin layers of meat found under slaughtered cows' skin), cow's stomach, and chicken feet that they wouldn't have eaten before the food price rises of the past few years. In Naogaon, respondents collect and eat wild green leaves previously perceived as inedible bush. One extremely poor day labourer ${ }^{9}$ and head of a four-member household collects the leftovers of a particular green leaf discarded by his neighbours, mixes it with pulses and prepares a curry with it. From his words in 2012: 'Five to six years ago, I could not even think of eating these. Now my family members are surviving by eating the leftovers of my neighbours.'

In urban areas, when children are hungry and mothers cannot afford proper food, they give them money to buy cheap fried or sugary snacks. Small grocery shops adjacent to slums sell sweets, chips and chocolates with attractive offers (e.g. free tattoos or stickers) and food vendors sell noodles, halim (a spicy meat and pulse stew), and so forth. Parents allow children to eat cheap processed and street foods, thinking that this will reduce pressure on regular meals (rice and other items). Children come to prefer processed food to home-cooked meals, with potentially adverse longer-term impacts on their health and nutrition.

\subsection{Adapting to higher prices}

When food price rises exceed absorptive capacities, people practise numerous incremental adjustments in their daily lives. In two of the three research sites, the study has been ongoing since near the peak of the global food, fuel and financial crisis, having started in early 2009. This means it is possible for us to see the shift from crisis-coping to subsistence shocks to longer-term adaptive strategies, to accommodate generally higher food prices - and the higher costs of living that go with those.

In both rural and urban places, people develop and utilise their own social capital as a support system. In urban areas, this has two layers - ties with individuals belonging to higher socioeconomic status than that of the poor (e.g. employers) and people from similar socioeconomic conditions. The employers of domestic maids often provide at least one meal every day in addition to a monthly salary. Maids prefer such conditions as they bring food home, and this cushions household spending against food price rises. Employers may also be a source of support at times of emergency, for instance, paying lump-sum costs such as children's school admission fees. They give or lend cash interest-free during crises, and on social occasions or festivals employers, neighbours and rich 
relatives gift cash, food items (sugar, milk, sweets and so forth) and clothes to poor people.

People also seek help from friends and relatives of similar socioeconomic conditions. A small business owner ${ }^{10}$ from Khulna mentioned, 'There are good times and there are difficult times. One might experience an accident or illness. While s/he waits to get back to his/her regular life, relatives, friends and neighbours extend help as much as they can.' Also, respondents borrow money during long-term crisis periods including while they are unemployed and for medical treatment when they do not have enough money to afford household consumption costs. Nevertheless, as they have poor socioeconomic status, these are small amounts to help meet immediate needs. In rural areas, relatives living in cities or abroad provide critical support during crises. They send money and gifts, and support migration to urban areas.

People in Khulna often use loans from microfinance institutions to smooth consumption instead of investing in income-generating activities (as they are officially supposed to). An extremely poor sharecropper ${ }^{11}$ in Naogaon shared his frustration: 'I expected to grow $200 \mathrm{~kg}$ of paddy but due to the weather, I ended up producing only $60 \mathrm{~kg}$. And so I had to borrow to eat'. Under similar conditions, people take loans from non-governmental organisations (NGOs) or neighbours. With the growing availability of cash credit, institutional and informal borrowing has become an adaptive practice.

Both in rural and urban areas, the observance of social and religious ceremonies or festivals has become limited to contain food spending. On the other hand, some urban folk arrange these events strategically to earn social capital and material goods in the form of gifts from invitees. A middle-aged slum dweller ${ }^{12}$ from Dhaka did the maths for us: 'Suppose a person would invite 200 people. It would cost him 30,000-40,000 taka. He would not face a loss because he will enjoy an "economy of scale" and people will bring presents. An invitee would think that cooking a feast at home would cost at least 1,000 taka while a present worth 500 taka will be enough to join the event.'

In rural areas in particular, people now grow their own vegetables to avoid buying them. In Khulna, NGOs provided gardening training after cyclone Aila, after which many women started growing vegetables in the empty space around their homes.
Our research shows various forms of migration. Poor women may take their children temporarily to their natal home; some men may then pressurise their wives to borrow money or bring 'dowry' from their parents. Sometimes income-earning people migrate for work and remit money home to the village. In some cases, the entire family migrates and starts a new life in a new place.

Farmers who own land mortgage out part of their assets when they fall into crises and require large sums of money. When they cannot repay this it eventually shrinks the household's cultivable land, affecting their subsistence.

In the city, we found that people resort to faith-based institutions (e.g. mazar-shrines of saints which people visit and donate money and food to as a religious ritual). These institutions offer free food daily. Our longitudinal case study of Shah Ali's Mazar, Dhaka, revealed that when food prices rise, the number of visitors eating regularly at the mazar increases. People travel by bus in groups even from distant places to eat at Shah Ali's Mazar, as the bus fare costs less than a decent meal.

Urban markets often reshape or take new forms according to demand. Our longitudinal study on markets shows that the area for meat and fish markets has been shrinking and replaced with lower cost vegetables. In Kalyanpur in Dhaka, two separate markets have developed. The 'market for fresh items' caters to higher income shoppers, and the 'low-cost market' where items may be nearly rotten and are in general of poorer quality sells to people with tighter budgets. In the low-cost market, chicken meat is sold in small portions and it is suspected that the 'fresh' chicken might be from poultry that has died of unknown causes. As it is cheap, nobody asks questions. Vegetables discarded at the 'fresh items' market' are sold here. Poor children and women collect these vegetables, cut out the rotten part and sell them on. Mobile food vans also ply their trade door-to-door, saving rental costs for the seller and a trip to market for the buyer. All these market innovations originated in the 2007/08 food price hike and have been sustained since.

\section{Resilience halfway through 4.1 Modest improvements}

Following Maslow's 'hierarchy of needs' model, ${ }^{13}$ we see people meeting their basic physiological needs but not higher level ones such as safety, security, self-esteem and self-actualisation. A day labourer ${ }^{14}$ in a rural area said, 'We, the husband and wife, 
often quarrel since we cannot adjust income and expenditure. Always there is discord about whether we should pay our son's school fee or spend money to meet household needs.' Even those who have been able to fulfil their physiological needs for a certain period cannot move upward in the need hierarchy as a result of uncertainty. A garment worker ${ }^{15}$ shared her anxiety about the future with the researchers in 2013:

\section{Although our income has increased, the food price has increased at the same rate. To some extent, we consume a little bit better quality food this year than that of the previous year. We want to continue feeding our children quality foods. Last year it was not possible, but this year we can. Their health is regaining. But we don't know what will happen next year.}

The modest improvement in her living standards was after the minimum wage had more than doubled in less than five years, the result of garment workers' protests about low wages at a time of sharply rising food prices in 2008 and 2011 (Hossain and Jahan 2014).

People on low incomes remain largely unable to achieve strong wellbeing outcomes around food security. Their resilience stops at coping and adaptive adjustments and does not reach the level of transformation. Transformational changes imply shifts in the nature of the system, from one pattern of livelihood and socioeconomic practice to a new and advanced one, which might include changes in technology, institutions, behaviour or culture (O'Brien 2011, cited in Béné et al. 2012: 22). After nearly a decade of food price volatility and food price rises, price shocks are no longer sudden onset events like cyclones, but slower burning; thus people's struggles are not seen as an acute crisis to be addressed immediately by the state. The status quo continues as the poor people themselves do not engage in collective action to bring community-level transformative changes by themselves or demanding that the state should do so, even though they know that they have rights in relation to the state. ${ }^{16} \mathrm{~A}$ small urban businessman ${ }^{17}$ commented:

Human being as the creation of Allah has the right to food permitted by Him. Poor people have the right to have three meals a day. Having fish or meat at least once or twice in a month is the right of every human being. But poor people are not enjoying this right properly.

\subsection{Accountable to the poor: none but the God Almighty Himself}

One major reason behind this complex of coping, adaptation and absence of protest to move forward to cause transformation is faith and fatalism. When asked about their food security, irrespective of location (rural and urban) or religion (Hindu and Muslim), respondents asserted their belief in their faith as a means of ensuring their food security. For Muslims, the Almighty Himself tests people by causing their sufferings. An elderly woman ${ }^{18}$ from Dhaka shared her perceptions about her right to food:

\section{Before birth, Allah Almighty has allotted a person's provision for food and sent him to the world. This is why, immediately after being born, a child drinks milk from its mother's breast. Having food is a birth right of human beings ascribed by Allah.}

The association between people's socioeconomic activities and their religious faith has gained attention in development literature recently (Aldashev and Platteau 2014). According to the World Values Survey (2012), ${ }^{19}$ Bangladesh scores highly for traditional and survival values. Traditional values emphasise the importance of religion, parent-child ties and family obligations. Survival values imply higher priority of security over liberty and abstinence from political action. We argue that the combination of these values leads to fatalism. Fatalism may be defined as 'the belief that life events are predetermined and inevitable, or (at the least) out of one's own control' (Kayani, King and Fleiter 2011). Our research shows that while reasoning about price volatility, people often mix up fatalism and state failure. For instance, an elderly farmer ${ }^{20}$ from the rural area shared his worldview about Allah and the responsibility of accountable institutions:

\section{It's the responsibility of Allah and the Government is a mere instrument through which we can enjoy the right of food. The Chairman, members and different organisations will ensure the right of food for us. Their duty is to coordinate between the government and the people.}

However, a recent urban migrant ${ }^{21}$ expressed the vulnerability of poor communities to administrative neglect, 'We are poor people, we do not have an umbrella over our heads, nor land under our feet; if we seek help from them [local government representatives] they chase us away saying we smell bad.' Another respondent ${ }^{22}$ said, 'People can ask for food to the government too, but does the government respond? Everyone has demands and rights to the government. But, government does not provide food for free.' The respondents ${ }^{23}$ are well aware of the lack of accountability of government actors: 'Before the election, the political candidates embrace us like brothers no matter how dirty or smelly we are. Once we vote for them and they 
win the election, they treat us like strangers.' This powerlessness among the poor to change the status quo of governance and accountability in turn reinforces their trust in God to support them during crises; as one female respondent ${ }^{24}$ said: 'Allah creates human beings; he will keep us alive. Our situation will go on like this as long as we survive.' In a similar vein, a participant $\mathrm{t}^{25}$ in a focus group discussion in Dhaka with male respondents opined,

\section{As a human being I want to live with all the privileges and amenities such as my accommodation, food, health care, and other essential things - these are my rights. However, the rights are coming from Allah. The power to cast vote is also a divine affair. It is the Allah's will that we cast vote and try doing well for ourselves and society.}

This worldview of the people that blends governance and rights with religion contributes to their acceptance of their situation as given. 'Without the wish of Allah no leaf can even swing. Thus, no one can do anything without the wish of Allah' said a farmer ${ }^{26}$ from Naogaon. Thus, trust in God and distrust towards institutional support together enforce two things. First, people continue to strive by coping and adapting. An Aila-affected small farmer ${ }^{27}$ from Khulna justified, 'If I do not work how Allah would give me food? The more you work, the more kind Allah will be upon you.' Second, they form their own informal social networks: 'There is a provision made by Allah to provide one or two meals to the hungry neighbour and obviously this is a right of a neighbour to another neighbour,' opined a house helper ${ }^{28}$ from Dhaka. An elderly woman ${ }^{29}$ explained the relationship between parents and children: 'It is the responsibility of the parents to feed their children and the Almighty Allah will arrange food for parents. When the parents grow old they have right to receive food from their children.' The reliance on God thus helps poor people cope psychologically and sets the rules for informal social protection.

\section{Notes}

1 Bangladesh is among 18 countries in the world that have shown extraordinary progress in terms of the Human Development Index (ranked 142nd in 2014). In 2014, UNDP introduced a Gender Development Index where Bangladesh ranks 107th, well ahead of India and Pakistan at 132nd and 145th place, respectively (UNDP 2014). In terms of the multidimensional poverty index, Bangladesh $(0.237)$ ranks higher than India (0.282) and is in the same position as Pakistan (UNDP 2014).

2 The World Bank reports that income inequality remains high in the country. Bangladesh has

\section{Conclusion}

In conclusion, we argue that while successive governments in Bangladesh have shown measurable progress in economic growth and poverty reduction, these positive trends do not help us to understand the way people's feelings of lack of control over rapidly changing lives and livelihoods are undermining their transformative capacity. Public policy needs to take more account of the wellbeing dimensions of rapid economic growth, particularly in an open globalised economy like Bangladesh where people are exposed to global shocks and trends.

The resilience of people living in the research sites has been reflected through different coping strategies for surviving the negative effects of food price volatility. The strategies include adjustments in food consumption through shifting to low-cost alternatives, consuming what they were not used to eating before, changing cooking patterns and depending more on processed foods. When food price volatility exceeds capacity to cope, adaptive strategies include using informal social capital, turning to faith-based organisations, sending women and children to earn income, migrating in search of work and making innovations in the market. People on low incomes in Bangladesh circle around these coping and adaptive strategies in an attempt to cater for their current needs. Nonetheless, the component of wellbeing that relates to being more in control of one's economic status remains unachievable. People are not managing to change their situation and the available government support does not help them to pursue such transformation. Inadequate, ineffective and unaccountable institutions give people reason to depend more on Divine power. On the one hand, people's continuing struggle is motivated by a belief that everything is God's will and, on the other hand, this belief keeps them from being united in realising their rights from accountable authority.

almost 81 million citizens living within the US $\$ 1.09-$ US $\$ 2.00$ per day range. While the cost of basic needs-based poverty headcount rate has declined rapidly in the past three decades, vulnerability has not (World Bank 2012: xii).

3 Focus group discussion with male participants, Dhamurhat, Naogaon, 18 September 2013.

4 Focus group discussion with female participants, Kallyanpur, Dhaka, 21 September 2013.

5 Focus group discussion with female participants, Kallyanpur, Dhaka, 15 December 2014.

6 Household case study, Dhamurhat, Naogaon, 28 August 2013. 
7 Focus group discussion with female participants, Kallyanpur, Dhaka, 21 September 2013.

8 Focus group discussion with male participant, Kallyanpur, Dhaka, 13 August 2013.

9 Household case study, Dhamurhat, Naogaon, 28 August 2013.

10 Focus group discussion with male participants, Koyra, Khulna 29 August 2013.

11 Household case study, Naogaon, 27 September 2014.

12 Household case study, Kallyanpur, Dhaka, 21 September 2014.

13 In Maslow's seminal work, 'A Theory of Human Motivation' (1943), he stated that human needs can be represented in a hierarchical way, where the most fundamental level of needs will be at the bottom and the need for self-actualisation will be at the top. As per his model, the primary-level need of every human being is the physical need, also known as physiological needs (Jahan et al. 2013: 24).

14 Household case study, Naogaon, 28 September 2014.

15 Household case study, Kallyanpur, Dhaka, 26 September 2013.

16 For detail, see Hossain and Jahan (2014).

17 Focus group discussion with male participants, Kallyanpur, Dhaka, 6 September 2014.

\section{References}

Aldashev, G. and Platteau, J.P. (2014) 'Religion, Culture, and Development', Handbook of the Economics of Art and Culture 2: 587-631

Béné, C.; Wood, R.G.; Newsham, A. and Davies, M. (2012) Resilience: New Utopia or New Tyranny? Reflection about the Potentials and Limits of the Concept of Resilience in Relation to Vulnerability Reduction Programmes, IDS Working Paper 405/CSP Working Paper 006, Brighton: IDS

Cutter, S.; Barnes, L.; Berry, M.; Burton, C.; Evans, E.; Tate, E. and Webb, J. (2008) A Place Based Model for Understanding Community Resilience to Natural Disasters', Global Enwironmental Change 18.4: 598-606

Gupte, J. and te Lintelo, D. (2015) 'Informal Work and Wellbeing in Urban South Asia: Who Succeeds, Who Fails and Under What Conditions?', unpublished report, Brighton: IDS

Heltberg, R.; Hossain, N.; Reva, A. and Turk, C. (2012) 'Coping and Resilience During the Food, Fuel, and Financial Crises', Fournal of Development Studies 49.5: 705-18

Hossain, N. and Jahan, F. (2014) The Food Riots that Never Were: The Moral and Political Economy of Food Security in Bangladesh, Food Riots and Food Rights
18 Household case study, Kallyanpur, Dhaka, 26 September 2013.

19 World Values Surveys (WVSs) have been carried out in five waves in more than 70 countries. It provides a wealth of information on a broad range of topics such as work, family, gender, politics, religion, democracy and the environment.

20 Household case study, Koyra, Khulna, 28 September 2014.

21 Focus group discussion with male participants, Kallyanpur, Dhaka, 6 September 2014.

22 Focus group discussion with male participants, Koyra, Khulna, 29 August 2013.

23 Focus group discussion with male participants, Kallyanpur, Dhaka, 6 September 2014.

24 Household case study, Kallyanpur, Dhaka, 26 September 2013.

25 Focus group discussion, Kallyanpur, Dhaka, 12 August 2013.

26 Household case study, Dhamurhat, Naogaon, 23 September 2013.

27 Focus group discussion with male respondents in Koyra, Khulna, 1 September 2013.

28 Focus group discussion with female participant in Kallyanpur, Dhaka, 15 December 2014.

29 Household case study, Kallyanpur, Dhaka, 13 August 2013.

project report, Brighton/Dhaka: IDS/University of Dhaka, www.foodriots.org (accessed 5 August 2015)

Jahan, F.; Shahan, A.M.; Rashid, M.; Hassan, B. and Siddiki, O.F. (2013) Bangladesh Food Price Report 2012: Life in a Time of Food Price Volatility, Year 1 Results, Brighton: IDS

Kayani, Ahsan; King, Mark J. and Fleiter, Judy J. (2011) 'Fatalism and Road Safety in Developing Countries, with a Focus on Pakistan', Fournal of the Australasian College of Road Safety 22.2: 41-7

Levay, A.V.; Mumtaz, Z.; Rashid, S.F. and Willows, N. (2013) 'Influence of Gender Roles and Rising Food Prices on Poor, Pregnant Women's Eating and Food Provisioning Practices in Dhaka, Bangladesh', Reproductive Health 10.1: 53

Maslow, A.H. (1943) 'A Theory of Human Motivation', Psychological Review 50.4: 370-96

Matin, I. (2009) 'Implications for Human Development - Impacts of Food Price Volatility on Nutrition and Schooling', BIDS Policy Brief 901, Dhaka: Bangladesh Institute of Development Studies (BIDS)

O’Brien, K. (2011) 'Global Environmental Change II: From Adaptation to Deliberate 
Transformation', Progress in Human Geography 35.4: 542-49

Rashid, M.; Hasan, B. and Hossain, N. (2012)

'Bangladesh: Pathways and Impacts of Global Economic Shocks', in R. Heltberg, N. Hossain and A. Reva (eds), Living Through Crises: How the Food, Fuel and Financial Shocks Affect the Poor, New Frontiers of Social Policy 67865, Washington DC: World Bank

Sen, A. (2000) Development as Freedom, New Delhi: Oxford University Press

UNDP (United Nations Development Programme) (2014) Human Development Report. Sustaining Human Progress: Reducing Vulnerabilities and Building Resilience.
Explanatory Note on the 2014 Human Development Report Composite Indices Bangladesh - HDI Values and Rank Changes in the 2014 Human Development Report, http://hdr.undp.org/sites/all/themes/ hdr_theme/country-notes/BGD.pdf (accessed 5 August 2015)

World Bank (2012) Bangladesh: Towards Accelerated, Inclusive and Sustainable Growth - Opportunities and Challenges, Bangladesh Development Series, Volume 1, Overview, Dhaka: World Bank World Value Survey (2012) Values Change the World, www.iffs.se/wp-content/uploads/2012/12/ WVS-brochure-web.pdf (accessed 1 July 2015) 